\title{
Power to the people
}

\section{An analysis of the problems caused by an increasing energy demand.}

\section{Energy at the Crossroads: Global Perspectives and Uncertainties \\ by Vaclav Smil \\ MIT Press: 2003. 448 pp. \$34.95, £22.95 \\ Michael Grubb}

Energy and the environment are huge and complex topics, and this is Vaclav Smil's synthesis of a lifetime's study in these areas. It emerges as the most sober, thorough and thoughtful integrated text on energy available, and it embodies core facts and some fundamental truths that any analyst of energy issues should ponder.

It is rarely good practice to review a book chapter by chapter, but each of the six in Smil's opus merits specific mention. "Longterm trends and achievements" provides an overview of the extraordinary development of the world's energy system and the innovations that revolutionized the twentieth century. Smil doesn't shy away from recognizing the blessings of modern energy consumption, and the way these drove an explosive growth in demand. After some mind-numbing statistics on the expansion of world energy during the twentieth century, he refers to the drudgery of former village life and notes that "it is not easy to convey the liberating power of electrification ... no other kind of energy affords such instant and effortless access." Electrification also revolutionized manufacturing even more than steam engines did. Did you know that electric motors consume two-thirds of all electricity in the United States?

In "Energy linkages", Smil explores how energy statistics relate to the world, with close attention to energy demand. Energy intensities - the ratio of countries' energy use to their gross domestic product - "confirm and reinforce some widely held snapshot notions about the economic fortunes of nations". Yet he also warns against over-reliance on aggregated numbers, and notes huge measurement problems (energy intensities for China differ by a factor of six according to whether currency exchange uses conventional rates or those corrected by purchasing-power parity — "both are clearly wrong").

Smil goes on to delineate six key variables that influence national energy intensity. $\mathrm{He}$ lays out the volatile history of energy prices and the distinction between market and real costs of energy. He also charts the relationship between energy and quality of life: on all the key indicators, he concludes, quality of life is highly correlated with energy consumption during basic economic development, but is almost completely uncorrelated once countries are industrialized.

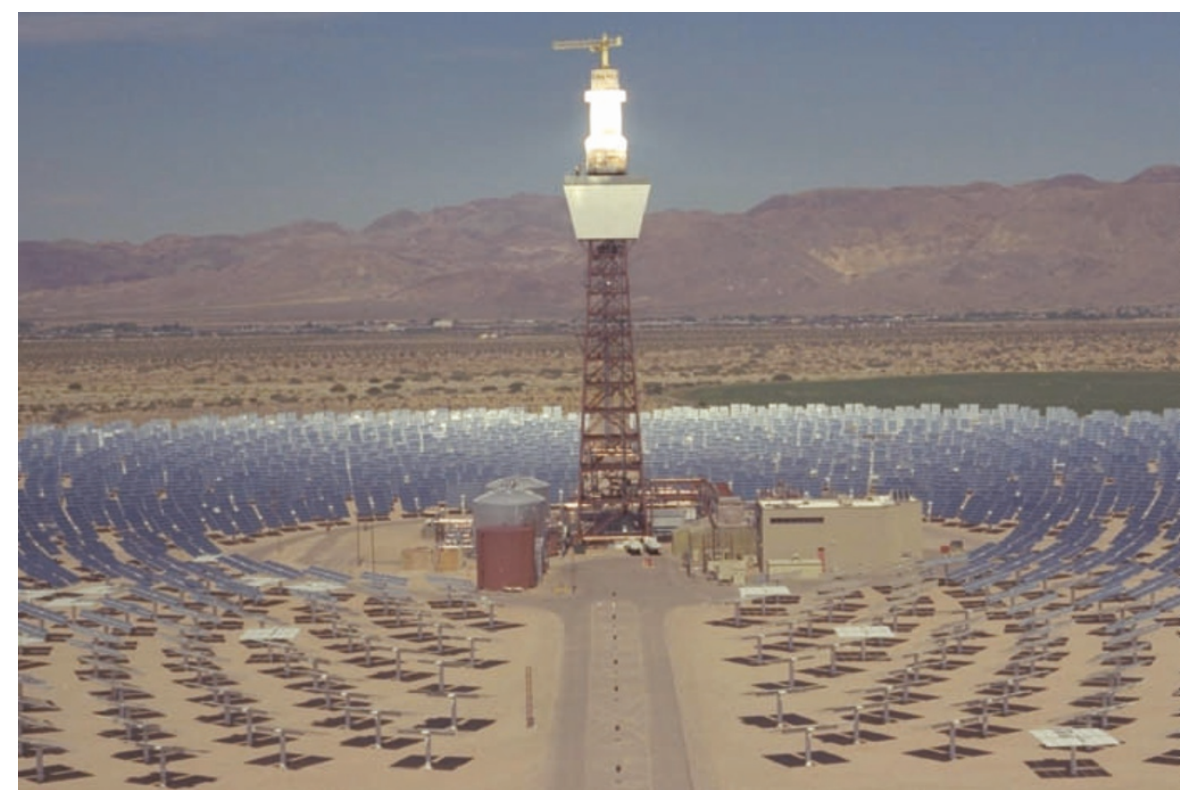

Generation ex? Solar Two, the world's largest solar tower, stopped producing electricity in 1999.

His third chapter, "Against forecasting", is by far the most comprehensive and damning demolition of energy forecasting I have seen. It is sobering to be reminded that only thirty years ago there were serious predictions that nuclear power would account for more than $90 \%$ of new construction by the start of this century, with equally far-fetched, unfulfilled and extraordinarily expensive programmes for coal, including the ill-fated US Synthetic Fuels Corporation.

The "eternally receding goal" of fusion power makes me similarly uneasy about the reviving fad for governments to reach for technology fixes to ease resurgent energy concerns. The human, institutional and policy element is vital too in energy demand illustrated perhaps most starkly by the fact that, during the last six years of Mao's rule, Chinese energy intensity rose by $34 \%$, then fell under Deng Xiaoping's liberation by a staggering 60\% from 1980 to 1995, wrongfooting the analysts.

Buried within the chapter is another indication of why Smil deserves to be taken so seriously. A chart of the range of energy forecasts made in 1983 for global demand in the year 2000 shows that almost all the big institutional forecasts were far too high, that 'soft energy' optimist Amory Lovins was far too low, and that Smil was accurate to within 3\%. But he modestly passes this off as chance and goes on to demolish both the history of energy forecasting and the pillars that support it. The two big persistent errors, he says, have been the "spell cast by the mood of the moment ... and infatuation with novelties and simple, magical solutions through tech- nical fixes". Smil concludes that what we need in the face of such intrinsic uncertainties are more, serious "normative scenarios, outlining what should happen rather than what is likely to happen" - futures to guide us, not forecasts to fool us.

The chapter on "Fossil fuel futures" should also be compulsory reading for the confused. In particular, I have never seen a fuller or a fairer account of the perpetual debate about oil and gas resource depletion. The pessimistic school is pitched against the professional optimists, who can reasonably claim to have history on their side in predicting that we will continue to find more oil. My own view is that the pessimists may be closer to the truth on conventional oil than they are on gas, but on fossil fuels overall the debate misses the important point. There is plenty of energy out there, both fossil and nonfossil, but getting it will require huge new investment - most of which is still targeted towards getting at carbon more cheaply, rather than developing alternatives.

In addressing non-fossil energies, Smil's experience and ecological professionalism come to the fore. Renewable energy offers credible alternatives but this is not an easy solution. Smil is particularly sceptical about harnessing even more of the world's net primary product for biomass energy, and uses basic biochemistry to explain that ethanol production based on yeast-mediated fermentation of starchy crops can use only "a small fraction of the phytomass present in relatively expensive feedstocks". This highlights how the book's depth is both its weakness and strength: the heavy technical content makes 
for hard reading but, when translated, it explains the fundamental reason why the ethanol subsidies for which the rich world's farmers lobby will do nothing for energy supply - unlike some of the other biomass energy routes.

Wind is perhaps the most interesting renewable: "generating $20 \%$ of US electricity demand would require less than $1 \%$ of land in the contiguous US, of which less than $5 \%$ would actually be taken up by the turbines themselves." The constraints will be those of systems and time, not natural resources. This is particularly true of the hydrogen economy, where Smil offers well-judged cautions and questions about current enthusiasms.

In his concluding chapter on possible futures, Smil emphasizes the complexities and timescales of change, which leads him to be generally conservative in the short term but with a broad long-term vision of what might be possible. This is true for both supply and demand: despite the book's emphasis on energy efficiency, Smil dismisses the fantasies of tenfold improvements being accomplished within a single generation.

Smil has the wisdom to frame the really big issues. He rejects the wishful thinking that the problems of energy are not real and the false hopes that they will go away or solve themselves. Truth matters, and is found neither in the specific scare stories or techno-optimism of many environmentally oriented writers, nor in the growth-blinded pronouncements of economic modellers and forecasters.

Yet Smil derives two big questions from the fundamentals of each of these world concerns: "If our actions were guided by the two greatest concerns a sapient terrestrial civilisation can have - for the integrity of the biosphere and for the dignity of human life — then it would be inescapable to ask the two most fascinating questions in energy studies: what is the maximum global TPES [primary energy supply] compatible with the perpetuation of vital biospheric services, and what is the minimum per capita energy use needed for a decent quality of life?" Smil says these questions are rarely asked, not only because they are extraordinarily difficult to answer, but because they demand clear moral commitment. Charting the energy horizons of environment and inequality, his conclusion boils down to Ghandi's famous dictum: the world has enough for everyone's need, but not enough for everyone's greed.

The policy implications outlined by Smil are not simple. How to promote efficiency and innovation without increasing consumption? How to reduce energy use among those who already overconsume fuel and boost it among those who don't? "When facing so many uncertainties, we should pursue any effective means that bring us closer to those goals," with "no categorical exclusion of certain ingredients (such as nuclear or big dams), no inflexible insistence on what is best."
This book should change the map by which we navigate the new energy century. In its intellectual content it is a great book, standing head and shoulders above most integrated writings on energy and environment. The complex, dense prose and tendency for rigorously balanced views may inhibit readers, but the book's underlying themes could and should prove the book's legacy. For example, Smil discusses the essential unpredictability and openness of energy futures, and provides a comprehensive critique of the notion that incessantly rising energy demand in industrialized countries is associated with increasing welfare though doing anything about it will not be easy. The book has gone straight to the top of my reading recommendations for my students. And for the serious technical analyst of energy systems, there is nothing better. Michael Grubb is professor of Climate Change and Energy Policy, Imperial College London, Exhibition Road, London SW7 2BP, UK.

\section{Autistic genius?}

\section{Autism and Creativity: Is There a Link between Autism in Men and Exceptional Ability?}

by Michael Fitzgerald

Brunner-Routledge: 2003. 304 pp.

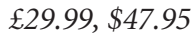

\section{Autism: Mind and Brain}

edited by Uta Frith and Elisabeth Hill Oxford University Press: 2003. 298 pp.

$£ 70, \$ 110$ ( $h b k$ ); $£ 29.95, \$ 49.50$ (pbk)

\section{Allan Snyder}

We tend to see only the whole - it takes insights from abnormal minds to appreciate how the brain assembles the parts. So could studies of autism reveal insights into creativity? It seems unlikely. The classical portrait of autism includes low intelligence, significant learning disabilities, memory by rote, literalness and a rigid insistence on sameness. Even autistic savants, known for their extraordinary mental feats, are not creative. Rather, they adopt a form of mimicry, probably due to privileged access to non-conscious processes. Beate Hermelin, an expert on autism, says that no savant will discover a new mathematical theorem, initiate a novel stylistic movement, or render a revealing interpretation of a Beethoven piano sonata.

But as these two superb new books demonstrate, our view of autism is radically transforming. It now embraces the classical picture of severe mental impairment at one end of the spectrum and possibly Nobelprizewinning creative genius at the other. Both extremes have in common certain core autistic features, such as preoccupation with detail, obsessional interests and difficulties in understanding another person's perspective.

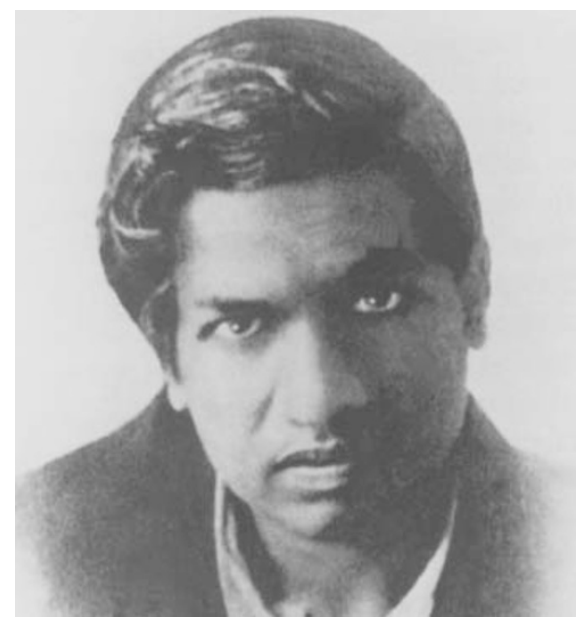

Did autism help shape the thinking of Indian mathematician Srinivasa Ramanujan?

Michael Fitzgerald, author of Autism and Creativity, says that some aspects of highfunctioning autism and Asperger's syndrome enhance creativity. Because these developmental disorders are mainly genetic in origin and largely affect men, he believes that creativity in a broader sense is predominantly the result of genetic rather than environmental factors: "The view that geniuses began their lives made from the same material as the rest of us ... is false." He then engages in retrospective diagnosis to support such claims, declaring that several individuals "with creativity of genius proportions" fit the high end of the autistic spectrum. These include Isaac Newton, the philosopher Ludwig Wittgenstein, mathematician Srinivasa Ramanujan, Lewis Carroll, the poet W. B. Yeats, and politicians Keith Joseph and Eamon de Valera. Apparently Hitler too had autistic traits.

Fitzgerald's thesis is not new. Hans Asperger spoke of "autistic intelligence" as being intelligence of "true creativity", adding "it seems that for success in science or art a dash of autism is essential." Oliver Sacks suggested that Wittgenstein had autistic traits. So too did Einstein, van Gogh and possibly Bill Gates, according to Temple Grandin, who is herself autistic. Asperger even noted that the autistic mind is an extreme variant of male intelligence. Despite these earlier revelations, Fitzgerald's tantalizing book is a must read, as are Simon Baron-Cohen's brilliant contributions to this area, such as The Essential Difference (Perseus, 2003).

The fact that genius can fall within the autistic spectrum challenges our deepest notions of creativity. Are there two different routes to creativity: normal and autistic? The normal mind is good at recognizing the gist of something but poor at recalling details. This, I believe, is because the brain forms concepts or mental models that encapsulate the familiar. Concepts impart automatic judgements and confer intuition, but hide details from conscious awareness. As a result, we see the whole but not the parts. In contrast, the 